\title{
Building local capability in an international playing field
}

Development of local competencies Experience of IFP School and IFP Training 


\section{Development of local competencies in oil and gas countries}

- Local content policies, strategies of all concerned companies

- Why is this development a worldwide challenge?

- Workforce: major changes

- Operational integrity: a concern for all stakeholders

- Initial qualification: a concern for the industry

- Technologies: diversity, complexity and rapid evolution

- Technical training needs time, dedication and continuity

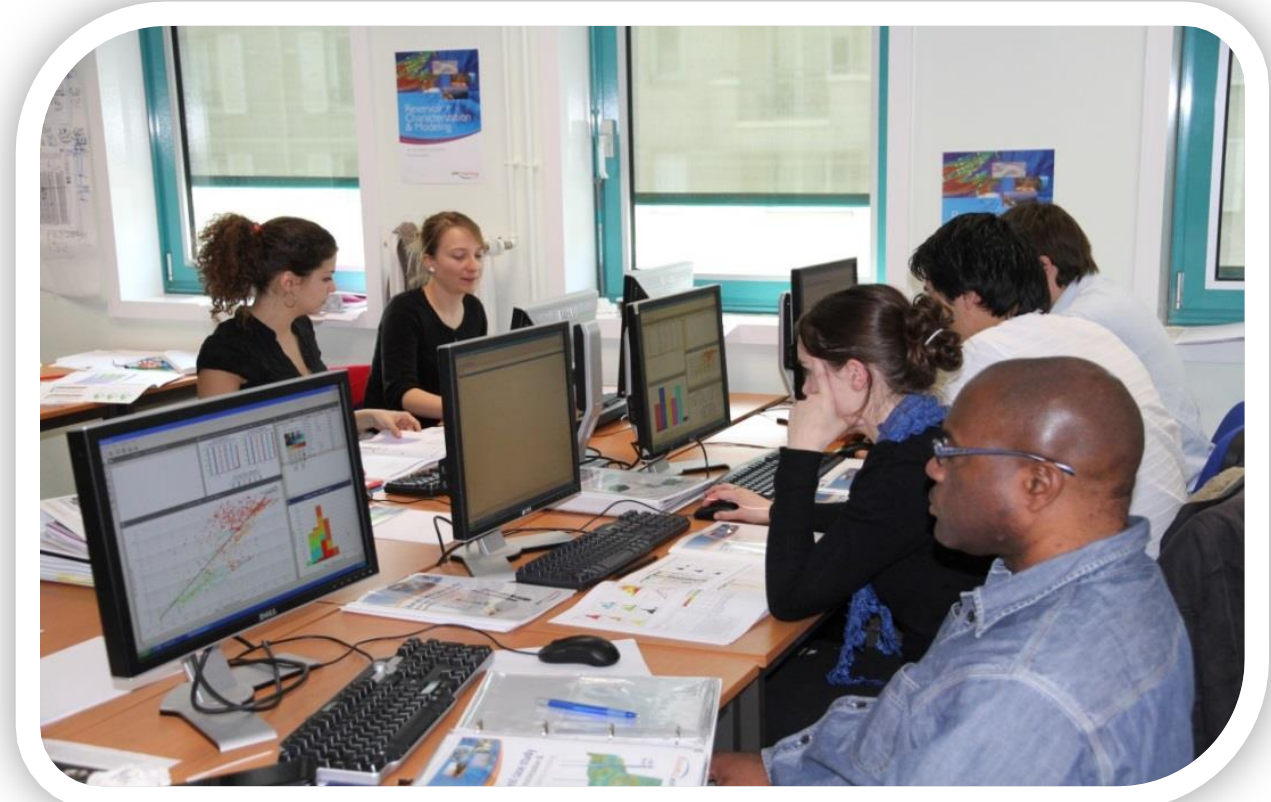




\section{Development of local competencies in oil and gas countries}

Facts and challenges

- Main conclusions of the IEF 2009 symposium in Doha on HR issues

- For the industry

- Recruit locally

- Cooperate with local universities

- Encourage partnerships between local and international universities

- For governments

- Invest in education and R\&D

- Stimulate cooperation between public and private interests

- For all actors

- Avoid stop-and-go policies: training needs insulation from boom \& bust cycles

- Avoid free-market-only policies: training needs collaboration 


\section{Development of local competencies in oil and gas countries}

Issues and actors

- Various partners ...

- Local or international universities / institutes

- Local or international training organisations

- National or international oil and gas companies

- ... for various partnerships

- Offshore campus

- Offshore programs

- Academic partnerships 


\section{- What is competency?}

- Les compétences sont les capacités d'un individu à exercer une fonction ou réaliser une tâche, généralement dans le cadre d'un travail en entreprise (Wikipédia Français)

- A standardized requirement for an individual to properly perform a specific job (Wikipedia English)

- For a training company, development of competencies relies on four elements:

$>$ Motivation $=$ what I want to do

$>$ Knowledge $=$ what I know

$>$ Knowhow $=$ what I am able to do

$>$ Attitude $=$ what I do and how I do it

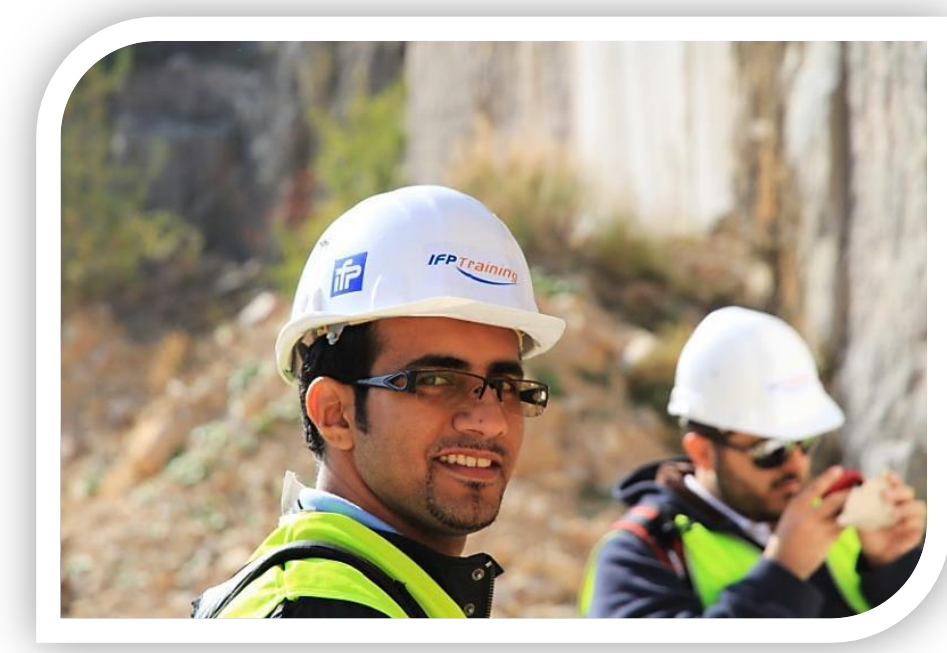

Development of competencies is linked to experience

Training is a catalyst and a booster 


\section{Development of local competencies in oil and gas countries}

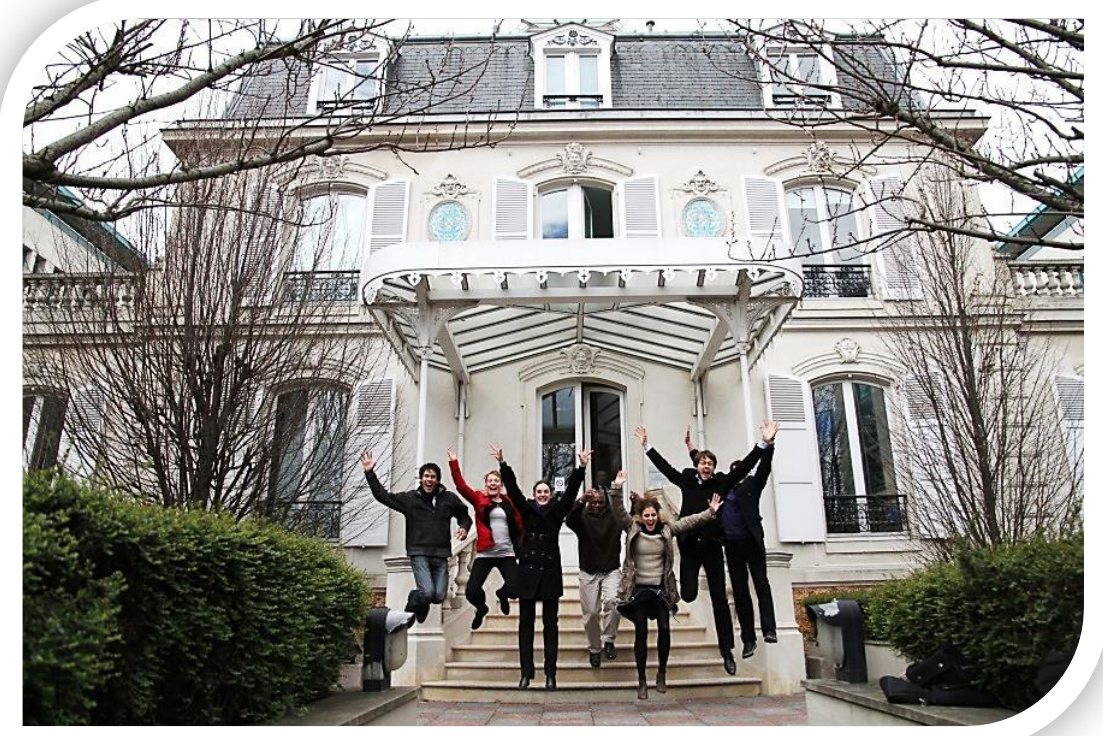

- IFP School

- Graduate school

- Programs cover the whole oil and gas chain

- Master or PhD level

- 600 graduates a year, 50\% foreigners

- Students from 50 countries

\section{- IFP Training}

- Subsidiary of IFP Energies nouvelles (IFP En) for continuing education

- Courses address all issues of the oil and gas industry

- Young or experienced professionals

- From operators and technicians to engineers and managers

- 15000 professionals, from 80 countries, trained every year

- Long training programs in Algeria, Angola, Bahrain, Cameroun, Congo, Gabon, Morocco, Myanmar, Russia, Saudi Arabia, Venezuela, Yemen, ... 


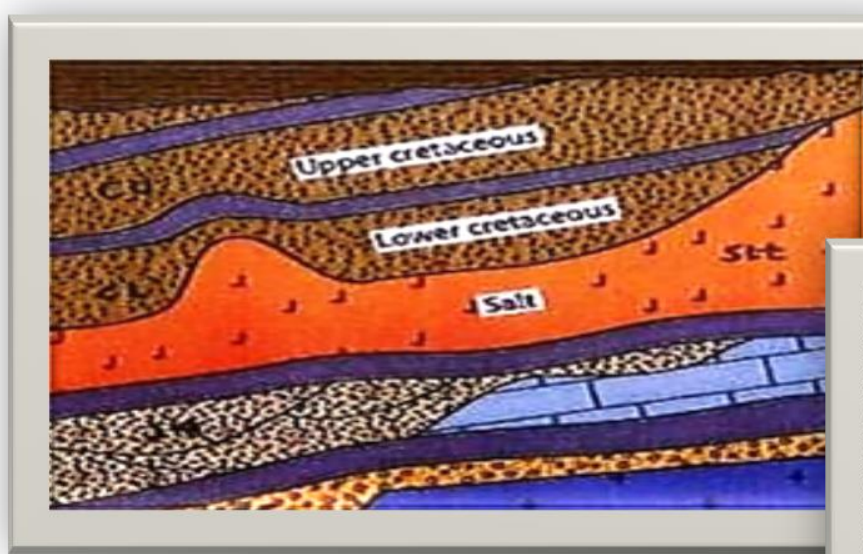

Experience of IFP School and IFP Training

... back

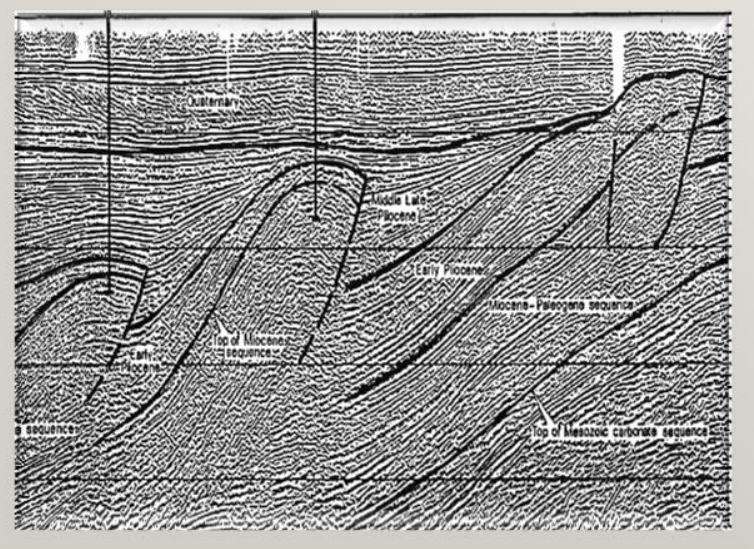

From concepts ...

\section{and}

forth.

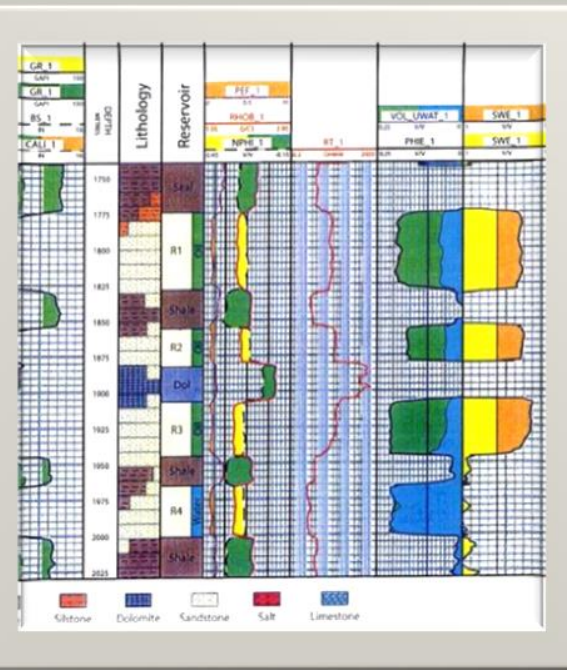

... to practice ... 


\section{Example: Master in Petroleum Engineering in Nigeria}

- Established 10 years ago, some 200 graduates active in the Nigerian O\&G sector

- Industrial partners: Total and NNPC

- Academic partner: Uniport (University of Port-Harcourt)

- Challenge: build a program at an international standard, with sustainable growth

- IFP School / IFP Training: global engineering, students' selection, academic coaching and assessment, lecturing $50 \%$ of the program

- Foundation of the Institute of Petroleum Studies

Lessons

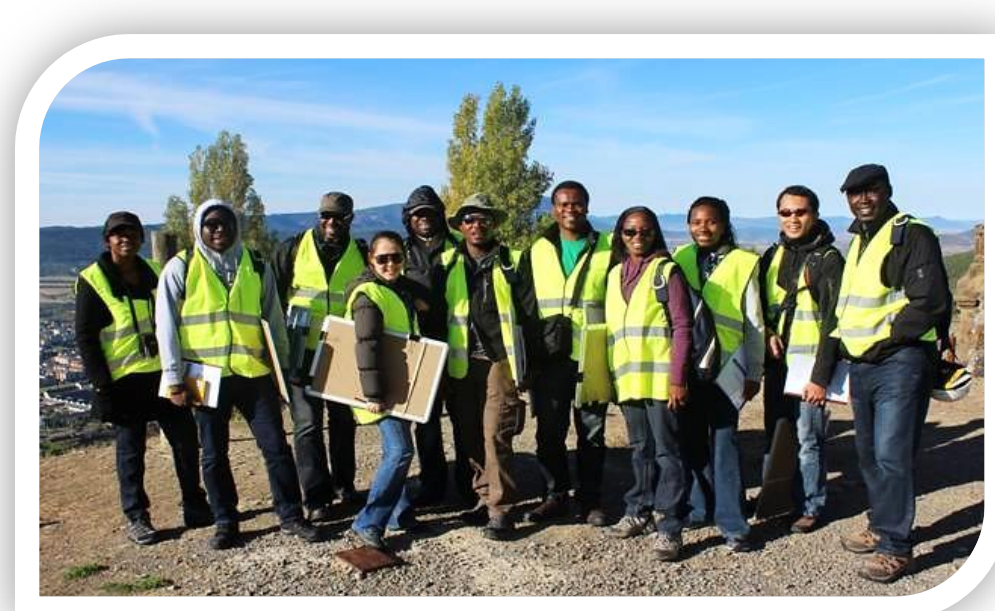

$\checkmark$ Recognized success of a program at IFP School's standards

$\checkmark$ Importance of industrial and academic partnerships 


\section{Example: Master in Petroleum Geosciences in Malaysia}

- Sponsor: PETRONAS and University Partner: UTP

- Multidisciplinary programme: 200 days

- Courses content: 11 modules, with progressive transfer to UTP

- Geology, Geochemistry

- Well log analysis, Seismic interpretation

- Basin assessment

- Reservoir characterisation and modelling

\section{Other Masters}

- Petroleum Geosciences in Venezuela

- Downhole and Surface Production in Algeria

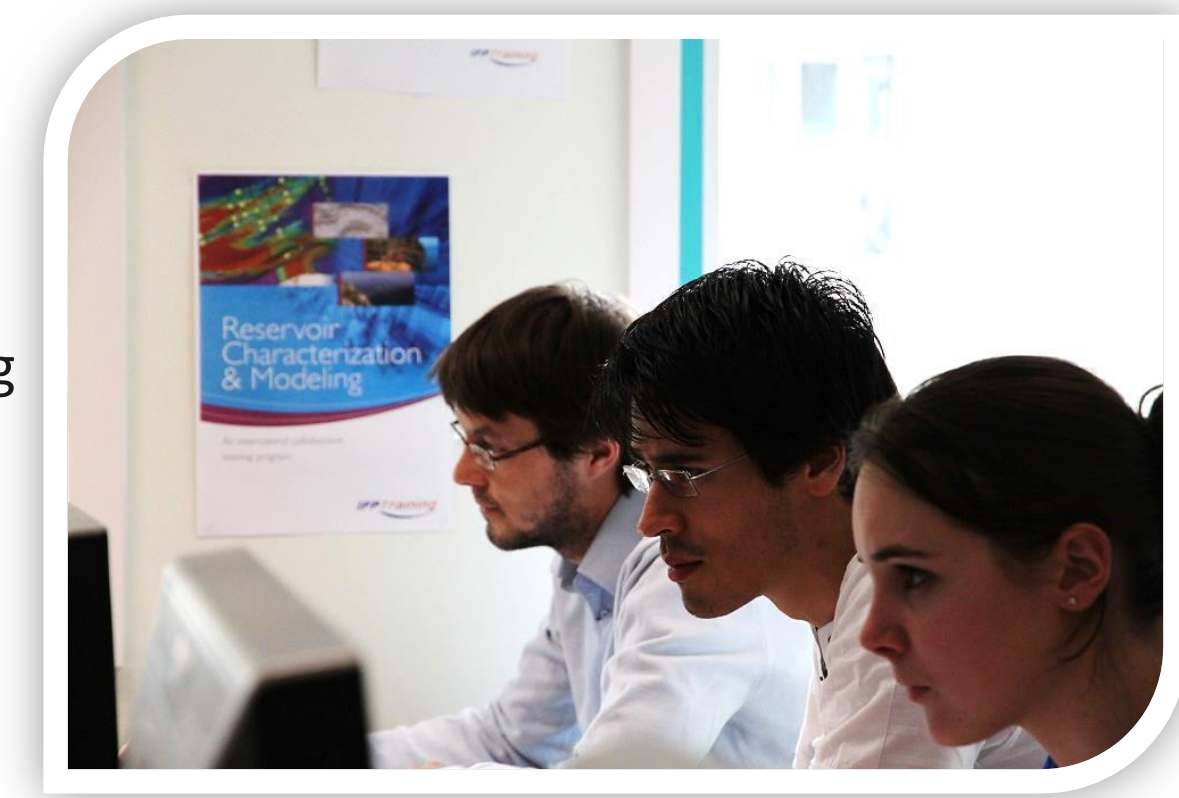




\section{Development of local competencies in oil and gas countries}

Experience of IFP Training

Foundation training programs in

Geology, Geophysics, Reservoir Engineering

Drilling \& Completion, Subsurface \& Production

- Example: Graduate Diploma in Petroleum Geosciences

- Duration: 12 weeks

- Based on practical case studies (hands-on), workshops, field trips

- Course content: 3 parts (12 modules)

- Foundations in Geoscience and Petroleum System Analysis

- Reservoir Identification and Characterization

- Basin Analysis and Prospect Evaluation

- Internship: 4-month work with project report, presentation and defence (jury)

- Project and internship within the company 
Example: Alternating training programs in Geosciences and Reservoir Engineering

- On the Job Training in Venezuela - Learn \& Do

- Training period mixed with OJT in Geosciences or in Reservoir Engineering (11 months)

- Training with IFP Training in alternation with hands-on workshops coached by experts from Beicip-Franlab (IFP En consulting subsidiary)

- Knowledge acquisition with IFP Training
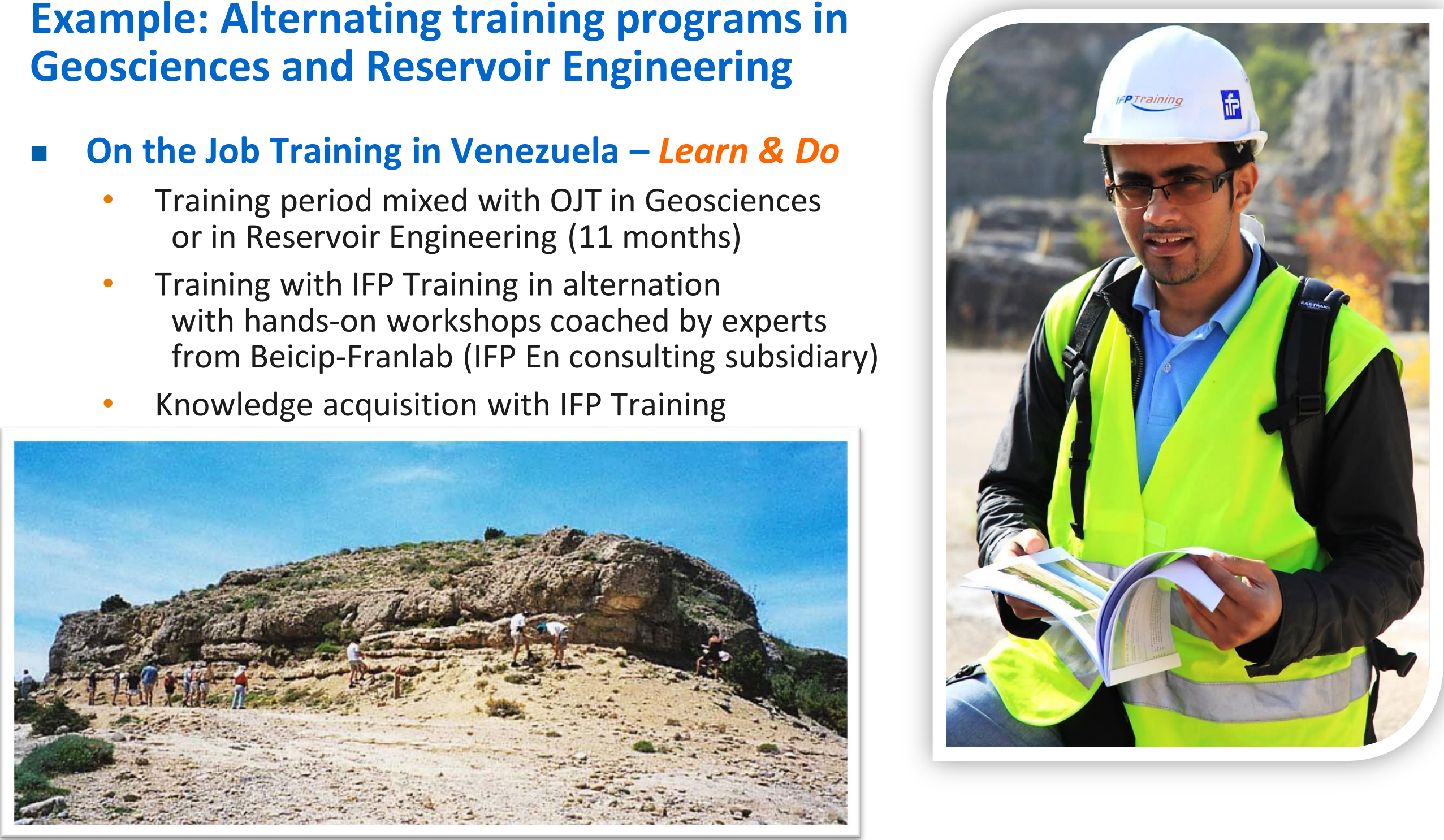
Experience of IFP Training

\section{Example: Operators Certification}

- More than 30 years of experience

- Some 3500 trained operators, downstream and upstream

- Success rate above $90 \%$

- Training program recognized by the industry

$\checkmark 1$ year, alternating classroom and on-site training

$\checkmark$ Important hands-on content, experienced trainers

$\checkmark$ Mentors in the company

- Strong growth worldwide, especially upstream

- Angola, Cameroun, Congo, Gabon, Myanmar, Nigeria, Venezuela,...

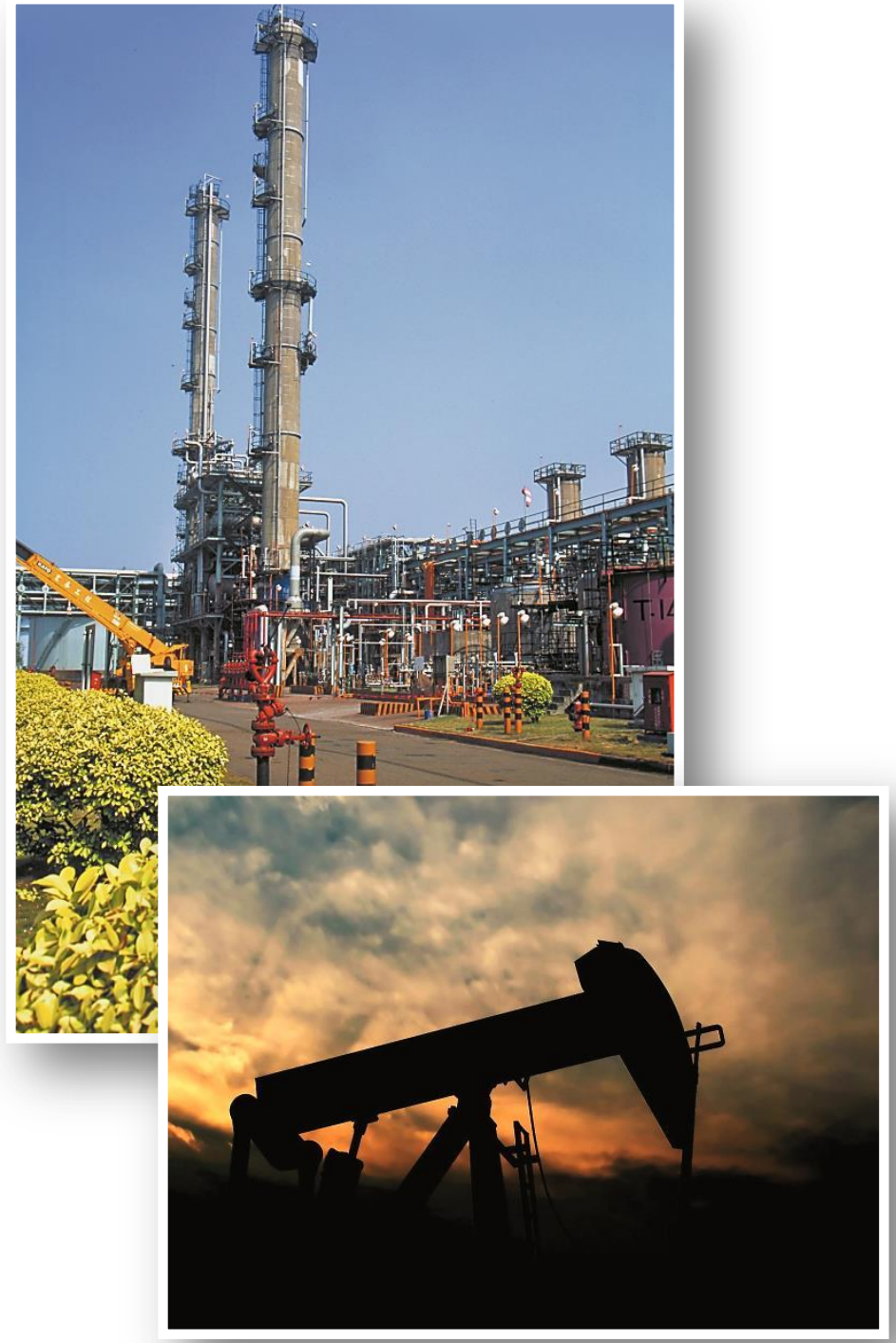




\section{Development of local competencies in oil and gas countries}

Conclusions

- It is a must!

- Main objective: speed up the qualification of the workforce

- Main challenge: devise focused and high-quality training schemes

- Development of local programs

$\checkmark$ increases intercultural understanding

$\checkmark$ decreases training costs

- Needs time, long-term policies, and partnerships

- No sustainable result can be achieved without continuity... 